At Turots: Jurnal Pendidikan Islam
Vol. 2, No. 2, Desember 2021, pp. 91-98
Print ISSN : 2656-7555 || Online ISSN : 2747-089X
http://journal.stitmadani.ac.id/index.php/JPI/index

\title{
Pengelolaan pendidikan islam pada perguruan tinggi perspektif manajemen pemasaran
}

\author{
Qiyadah Robbaniyah a,1, Syaiful Anam a,2, Eka Safitri a,3 \\ a Sekolah Tinggi Ilmu Tarbiyah Madani Yogyakarta, Yogyakarta, Indonesia; \\ *1qrobbaniyah@gmail.com; ${ }^{2}$ anams9763@gmail.com; ${ }^{3}$ dindaekas@gmail.com
}

Received:

Revised:

Accepted:

KATAKUNCI

Manajemen

STIT Madani Yogyakarta

Implementasi Pemasaran

KEYWORDS

Management

STIT Madani Yogyakarta

Marketing Implementation

\section{ABSTRAK}

Pemasaran untuk lembaga pendidikan mutlak diperlukan karena persaingan antar Perguruan Tinggi semakin atraktif. Hal itu terlihat dari munculnya berbagai Perguruan Tinggi yang saling menawarkan keungulanya masing-masing. Perguruan Tinggi sebagai lembaga pendidikan yang mengemban tugas yang tidak ringan, sangat diperlukan sistem manajerial yang baik dalam semua segi yang ada di dalamnya.Penelitian ini merupakan penelitian kualitatif dan lapangan (fiel research), Teknik Pengumpulan data yang digunakan adalah observasi, dokumentasi, dan wawancara dengan pengujian kredibilitas data yaitu triangulasi teknik dan sumber. Implementasi pemasaran STIT Madani Yogyakarta sebagai berikut; (1) Strategi pemasaran; dalam mengidentifikasi pasar STIT Madani Yogyakarta membagi beberapa tingkatan pangsa pasar yaitu pondok cabang Bin Baz, pondok pesantren, SMA/SMK/MA Negeri ataupun swasta. Dalam menciptakan postioning di masyarakat STIT Madani telah menfokuskan bahwa STIT Madani Yogyakarta sebagai kampus Islam, berasrama serta bermanhajsalafus-sholeh. (2) Taktik pemasaran; dalam selling diperlukan adanya bauran pemasaran yang didalamnya harus terdapat diferensiasi sehingga dapat membedakan dan memudahkan dalam memasarkan produk kepada konsumen.

\section{Management of Islamic education in colleges from a marketing management perspective}

Marketing for educational institutions is absolutely necessary because competition between universities is increasingly attractive. This can be seen from the emergence of various universities that offer each other their respective advantages. Higher education as an educational institution that carries out a task that is not light, requires a good managerial system in all aspects in it. This research is a qualitative and field research (field research), the data collection techniques used are observation, documentation, and interviews. by testing the credibility of the data, namely the triangulation of techniques and sources. The marketing implementation of STIT Madani Yogyakarta is as follows; (1) Marketing strategy; in identifying the market STIT Madani Yogyakarta divides several levels of market share, namely the Bin Baz branch of the Islamic boarding school, other Islamic boardinschools, public or private SMA / SMK / MA. In creating postioning in the community STIT Madani has focused on STIT Madani Yogyakarta as an Islamic campus, boarding and practicing manhajsalafus-sholeh. (2) Marketing tactics; In selling, it is necessary to have a marketing mix in which there must be differentiation so that it can differentiate and make it easier to market products to 
consumers.

\section{Pendahuluan}

Pemasaran untuk lembaga pendidikan mutlak diperlukan karena persaingan antar Perguruan Tinggi semakin atraktif . Hal itu terlihat dari munculnya berbagai

Perguruan Tinggi yang saling menawarkan keunggulannya masing-masing. Perguruan Tinggi sebagai lembaga penyedia jasa pendidikan perlu belajar dan memiliki inisiatif untuk meningkatkan kepuasan pelangan (mahasiswa) karena pendidikan merupakan proses sirkuler yang saling mempengaruhi dan berkelanjutan. Oleh karena itu, diperlukan strategi pemasaran jasa pendidikan untuk memenangkan kompetensi antar Perguruan Tinggi serta untuk meningkatkan akselerasi peningkatan kualitas dan profesionalisme manajeman Perguruan Tinggi.

Sebagai salah satu komponen utama dalam sistem pendidikan, lembaga pendidikan sudah selayaknya memberikan kontribusi yang nyata dalam meningkatkan kualitas sumber daya manusia (SDM). Apabila lembaga pendidikan dianalogikan sebagai mesin produksi, maka kualitas output akan ditentukan oleh kualitas mesin tersebut. Artinya, pengelolaan pendidikan yang bermutu tidak terlepas dari fungsi-fungsi manajemen secara umum yaitu: perencanaan (planning), pengorganisasian (organizing), pengarahan (directing) dan pengendalian (controlling).

Pengelolaan pendidikan menjadi sangat penting, dimana pertumbuhan dan perkembangan lembaga pendidikan di pengaruhi oleh kemampuan administrator dalam melakukan scaning lingkungan eksternal, kompetitor lembaga lain, memperhitungkan kompetensi internal, harus dapat menciptakan strategi yang mempunin untuk memenangkan persaingan tanpa meningalkan esensi dari pendidikan itu sendiri .

Perguruan Tinggi harus memiliki -branding\| yang baik dan berusaha mempertahankannya untuk tetap eksis menghadapi persaingan antar-Perguruan Tinggi yang semakin ketat. -Branding\| adalah sebuah proses memperkenalkan "brand" sampai bagaimana lingkungan memberikan penilaian yang baik pada "brand" tersebut. Perguruan Tinggi yang tidak memiliki "branding" baik akan dilupakan oleh konsumennya yakni mahasiswa dan calon mahasiswa.

STIT Madani Yogyakarta adalah sekolah tinggi ilmu Tarbiyah yang berdiri pada tahun 2017 dengan SK DIRJEN DIKTIS KEMENAG RI: 3364 /2017. Program studi yang ditawarkan di STIT Madani Yogyakarta adalah Prodi Pendidikan Agam Islam dan Prodi Pendidikan Bahasa Arab. STIT Madani Yogyakarta beralamat di Jl. Wonosari Km. 10 Karanggayam Sitimulyo Piyungan Bantul Yogyakarta. Latar belakang berdirinya STIT Madani Yogyakarta bertujuan untuk mendidik para dai di jalan Allah yang cerdas dalam berdakwah sekaligus terampil melayani kebutuhan kesehatan masyarakat. Keunggulan STIT Madani Yogykarta adalah (1) Dosen yang kompeten dan professional, (2) Terintegrasi dengan kurikulum pesantren, (3)Mendapatkan mareti materi kepesantrenan seperti materi aqidah, akhlak, fikih, dan sebagainya (4) Asrama dan kegiatan belajar mengajar terpisah antara putra dan putri, (5) Lokasi Strategis, dekat dengan bandara dan terminal Bus (6) Menghadirkan lingkungan kampus dengan balutan nuansa Islami dan jauh dari kebisingan, (7) Program Arabic Day.

Pilar Pendidikan yang di usung oleh STIT Madani Yogyakarta adalah (1) Attitude yang Islami; Islamisasi kampus yang bertekad untuk mencetak generasi unggulan yang Islami. Generasi yang mampu merespon perkembangan dunia sekaligus tetap menjalankan kegiatan 
dakwah di jalan Allah Ta'ala (2) Knowledge (Cendikia); Kurikulum yang terintegrasi memadukan standar kompetensi dari KKNI dan Kepesantrenan dengan harapan mahasiswa/i akan menguasai pengetahuan dengan baik sehingga menjadi cendekiawan muslim yang mampu menguasai ilmu dunia dan akhirat (3) Skill yang Profesional; Dengan fasilitas laboratorium dan sarana penunjang lain, insyaallah profesionalisme SDM dapat kian kuat.

STIT Madani Yogyakarta merupakan sekolah tinggi kesehatan berlandasan Islam dan satu-satunya kampus yang mewajibkan untuk berasrama bagi mahasiswanya, pola pendidikan yang diusung oleh STIT Madani yaitu mengintegrasikan nilai-nilai agama dalam kehidupan sehari- hari . Sebagai sebuah lembaga pendidikan Sekolah Tinggi Ilmu Tarbiyah yang baru, STIT Madani Yogyakarta tentu memiliki konsep manajemen pemasaran peguruan tinggi tersendiri untuk dapat tetap eksis dan bertahan, Serta dalam menghadapi persaingan Sekolah Tinggi Ilmu Tarbiyah yang lainya.

Berdasarkan pemaparan diatas, peneliti tertarik untuk meneliti hal-hal yang berkaitan dengan manajemen pemasaran Perguruan Tinggi di STIT Madani Yogyakarta dilihat dari Produk yang ditawarkan, strategi penentuan harga, lokasi tempat jasa diberikan, promosi yang dilakukan, SDM dilihat dari kualitas, kualifikasi, dan kompetensi yang dimiliki oleh orang-orang yang terlibat dalam pemberian jasa, sarana-prasarana seperti apa yang dimiliki, dan manajemen layanan pembelajaran yang diberikan kepada konsumen sehingga manajeman pemasaran Perguruan Tinggi dapat terlaksana dan dapat bersaing dengan Perguruan Tinggi lainnya di Indonesia.

\section{Metode}

Penelitian ini digolongkan ke dalam jenis penelitian lapangan (field research), yaitu dalam proses perolehan data sesuai dengan sasaran atau masalah penelitian yang diperlukan sebuah informasi yang selengkap- lengkapnya atau sedalamdalamnya mengenai gejala-gejala yang ada dalam lingkup obyek penelitian. Dari gejala-gejala penelitian yang ada dalam penelitian ini bukanlah satu-satunya yang berdiri, melainkan saling berkaitan antara satu sama lain dalam kesatuan yang menyeluruh yang biasanya dikenal dengan pendekatan . Dalam penelitian ini, pengumpulan data menggunakan tiga metode utama yaitu : wawancara, observasi dan dokumentasi.

\section{Hasil dan Pembahasan}

\section{Manajemen Pemasaran di STIT Madani Yogyakarta}

Hasil dan Pembahasan dapat disajikan dalam subbab. Membahas secara jelas pokok bahasan sesuai dengan masalah, tujuan penelitian, dan teori yang digunakan. Pemasaran (marketing) adalah suatu proses sosial dan manajerial yang melibatkan kegiatan-kegiatan penting yang memungkinkan individu dan kelompok mendapatkan kebutuhan dan keinginan melalui pertukaran dengan pihak lain dan untuk mengembangkan hubungan pertukaran. Proses pemasaran sangat di pengaruhi oleh berbagai faktor seperti sosial, budaya, politik, ekonomi, dan manajerial. Akibat dari berbagai pengaruh tersebut masing-masing individu atau kelompok mendapatkan kebutuhan dan keinginan dengan menciptakan, menawarkan, dan menukarkan produk yang memiliki nilai komoditas (cimodity values).

Manajemen pemasaran atau marketing management berasal dari dua kata managemen dan marketing yaitu dua ilmu yang terpisah kemudian dipadukan dalam satu kegiatan. Artinya, fungsi-fungsi yang ada dalam kedua ilmu tersebut digabung dalam bentuk suatu kerjasama. Henri Fayol menyebutkan adanya lima fungsi manajemen yaitu planning, organizing, commading, coordinating, dan controlling (POC3). Sedangkan Luther Gulick menyatakan adanya tujuan unsur yang dihimpun dalam kata-kata POSDCORB yaitu planning, organizing, staffing, directing, coordinating, reporting, budgeting. Yang lebih sederhana fungsi-fungsi manajemen yang dikemukakan oleh G.R Terry dengan istilah POAC yaitu 
planning, organizing, actuating, dan controlling.7

Dari fungsi-fungsi manajemen yang dikemukakan oleh Terry dapat dilihat contoh penerapannya di dalam pemasaran Perguruan Tinggi. Misalnya untuk pelaksanaan marketing suatu produk Perguruan Tinggi perlu diadakan planning lebih dahulu. Planning tersebut dibuat berdasarkan data yang ada di Perguruan Tinggi. Misalnya planning daerah pemasaran, planning tentang harga, planning strategi yang akan digunakan dalam memasuki pasar, teknik promosi yang akan digunakan. Kemudian disusun organisasi yang jelas dan efisien, sehingga dengan jelas diketahui siapa yang bertanggung jawab, kepada siapa harus dipertanggung jawabkan, bagaimana koordinasi dalam Perguruan Tinggi. Jadi disini diperlukan suatu struktur yang jelas, sehingga tidak terjadi saling lempar tanggung jawab seandainya terjadi penyimpangan-penyimpangan dalam pekerjaan.

Actuating sebagai fungsi ketiga, yaitu melaksanakan pekerjaan bagaimana cara kerja, kemana harus harus pergi, kapan, dan sebagainya. Agar pelaksanaan pekerjaan berjalan dengan mulus, maka para pekerja perlu diberi insentif. Dengan demikian harus ditetapkan secara jelas tentang gaji, honor, uang lelah, dan sebagainya. Fungsi terakhir ialah perlu adanya control dari setiap pekerjaan yang dilakukan, control harus dilakukan sedini mungkin agar tidak terjadi kesalahn yang berlarut-larut. Jika terjadi penyimpangan dari planning yang telah ditetapkan maka perlu diambil tindakan pencegahan.

\section{Fungsi Marketing di STIT Madani Yogyakarta}

Untuk membentuk citra baik terhadap lembaga, dalam rangka menarik minat sejumlah calon mahasiswa, maka lembaga pendidikan (Perguruan Tinggi) telah mengunakan/mengembangkan berbagai upaya strategi yang dikenal dengan upaya strategi bauran pemasaran. Strategi ini termasuk ke dalam bidang total marketing plan.

Mahasiswa pilihan mahasiswa yaitu lingkungan sosio kultural (dari mana calon mahasiswa berasal, apakah dia cocok bergaul di lingkungan Perguruan Tinggi yang akan dia masuki), lingkungan politik dan hukum, lingkungan ekonomi dan teknologi, lingkungan kompetitif, dan lingkungan sumber daya. Semua lingkungan tersebut menjadi bahan pertimbangan calon mahasiswa untuk memasuki sebuah Perguruan Tinggi.

Apabila sebuah Perguruan Tinggi sudah mencoba melaksanakan kegiatan marketing yang berorientasi ke konsumen, maka seluruh personil staf baik dosen maupun tenaga administrasi harus menghayati apa misi mereka, apa bisnis mereka. Dengan pendekatan marketing memaksa dosen dan personil yang terlibat dalam Perguruan Tinggi untuk mengalisa intra dan ekstra kurikuler, fasilitas pendidikan, suasana belajar mengajar dan sebagainya. Sehingga seluruh kegiatan selalu terpusat kepada perbaikan mutu.

Dengan melaksanakan kegiatan marketing akan membantu Perguruan Tinggi menghadapi masa depan yang lebih baik. Ada dua usaha yang hendak dicapai oleh organiasasi non profit dalam kegiatan marketingnya yaitu mencari konsumen dan mencari dana dari donator. Namun, organisasi non profit seperti lembaga keagamaan, kesehatan, Perguruan Tinggi tidak senang mengunakan istilah konsumen tetapi mengunakan istilah spesifik yang sesuai dengan kegiatannya seperti jama`ah, anggota, pasien, para pendengar, siswa, mahasiswa, dan sebagainya. Organisasi non profit ini mencoba membangkitkan image positif dari anggotanya terhadap lembaga.

\section{Karakteristik Manajemen Pemasaran di STIT Madani Yogyakarta}

Karakteristik manajemen pemasaran islami mempunyai empat sifat yaitu :

a. Teistis (rabaniyyah)

Salah satu ciri khas manajemen pemasaran islami yang tidak dimiliki dalam pemasaran 
konvensional yang dikenal selama ini adalah sifat yang religius (dinniyah). Kondisi ini tercipta tidak karena keterpaksaan, tetapi berangkat dari kesadaran akan nilai-nilai religius, yang dipandang penting dan mewarnai aktivitas pemasaran agar tidak terperosok kedalam perbuatan yang dapat merugikan orang lain.

Jiwa seorang pelaku pemasaran islami menyakini bahwa hukum- hukum syariat yang teistis atau bersifat ketuhanan ini adalah hukum yang paling sempurna. seorang pelaku pemasaran islami meyakini bahwa Allah. selalu dekat dan mengawasinya ketika dia sedang melaksanakan segala macam bentuk bisnis. Dia pun yakin bahwa Allah akan meminta pertanggung jawaban darinya atas pelaksanaan syariat itu pada hari ketika semua dikumpulkan untuk diperlihatkan amal-amalnya di hari kiamat.

\section{b. Etis (akhlaqiyyah)}

Sifat etis ini sebenarnya merupakan turunan dari sifat teistis. Dengan demikian, Manajemen pemasaran islami adalah konsep pemasaran yang sangat mengedepankan nilainilai moral dan etika, tidak peduli apapun agamanya. Karena nilai etika adalah nilai yang bersifat universal, yang diajarkan oleh semua agama.

Untuk mencapai tujuan tersebut, Allah memberikan petunjuk melalui para rasul-Nya yang meliputi segala sesuatu yang dibutuhkan manusia, baik akidah, akhlak (moral, etika), maupun syariah. Dua komponen pertama, akidah dan akhlak bersifat konstan, keduanya tidak mengalami perubahan apapun dengan berbedanya waktu dan tempat. Sedangkan syariah senantiasa berubah sesuai dengan kebutuhan dan taraf peradaban manusia, yang berbedabeda sesuai dengan rasulnya masingmasing.

\section{c. Realistis (al-waqi'iyyah)}

Realistis (Al-Waqi'iyyah) manajemen pemasaran islami bukanlah konsep yang eksklusif, fanatis, anti-modernitas, dan kaku. manajemen pemasaran islami adalah konsep pemasaran yang fleksibel, sebagaimana keluwesan syariah Islamiyah yang melandasinya.

Manajemen pemasaran islami bukanlah berarti para pemasar itu harus berpenampilan ala bangsa Arab dan mengharamkan dasi karena dianggap merupakan simbol masyarakat barat. Syariah marketer adalah para pemasar profesional dengan penampilan yang bersih, rapi, dan bersahaja, apapun model atau gaya berpakaian yang dikenakannya. Mereka bekerja dengan profesional dan mengedepankan nilai-nilai religius, kesalehan, aspek moral, dan kejujuran dalam segala aktivitas pemasarannya.

\section{d. Humanistis (insaniyyah)}

Humanistis (insaniyyah) adalah bahwa syariah diciptakan untuk manusia agar derajatnya terangkat, sifat kemanusiaannya terjaga dan terpelihara, serta sifatsifat kehewanannya dapat terkekang dengan panduan syariah. Dengan memiliki nilai humanistis ia menjadi manusia yang terkontrol, dan seimbang (tawazun), bukan manusia yang serakah, yang menghalalkan segala cara untuk meraih keuntungan yang sebesar-besarnya. Bukan menjadi manusia yang bahagia diatas penderitaan orang lain atau manusia yang kering dengan kepedulian sosial.

\section{Unsur-Unsur Manajemen Pemasaran di STIT Madani Yogyakarta}

Unsur utama dalam pemasaran dapat diklasifikasi menjadi tiga bagian :

a. Strategi Persaingan yang terdiri atas : Segmentasi Pasar, Targeting, dan Positioning.

b. Taktik Pemasaran yang terdiri atas: Selling, Differensiasi, dan Bauran Pemasaran.

c. Nilai Pemasaran berupa Brand, Service, dan Process.

Unsur strategi persaingan (mind share strategy) meliputi:

a. Segmentasi pasar, yaitu tindakan mengidentifikasi dan membentuk kelompok pembeli atau konsumen secara terpisah. Masing-masing konsumen ini memiliki karakteristik, kebutuhan produk, dan bauran pemasaran tersendiri. Diketahui bahwa pasar jasa 
pendidikan dari sudut marketing secara sederhana dapat dikelompokkan ke dalam dua segmen pasar yaitu pertama, segmen pasar emosional yaitu kumpulan pelanggan yang datang mendaftar atau bergabung ke sebuah lembaga pendidikan karena pertimbangan religiousitas, pasar ini kurang memperhatikan harga kualitas, mutu dan ketersediaan jaringan (networking) yang memadai. dan kedua, segmen pasar rasional; adalah pelanggan yang benarbenar sensitive terhadap perkembangan dan kualitas mutu pendidikan.

b. Targeting, yaitu membagi pasar menjadi kelompok pembeli yang dibedakan berdasarkan kebutuhan, karakteristik, atau tingkah laku yang mungkin membutuhkan produk yang berbeda. Secara umum segmentasi pasar dapat dipilih berdasarkan segmentasi geografis, segmentasi demografi, segmentasi manfaat, psikologi, segmentasi sosioekonomi, segmentasi pengunaan, dan segemntasi berdasarkan jasa.

c. Positioning, yaitu penetapan posisi pasar. Karakteristik dan pembedaan (differensiasi) produk yang nyata yang memudahkan konsumen untuk membedakan produk jasa antara satu lembaga dengan lembaga lainya. Posisioning berkaitan dengan bagaimana pemasar membedakan jasanya dengan pesaing (memilih pesaing). Tujuannya adalah untuk membangun dan mengkomunikasikan keunggulan bersaing produk yang ada di pasar ke dalam benak konsumen.

Unsur taktik pemasaran (market share tactic) meliputi:

a. Selling yang terkait dengan penjualan.

Pengelola Perguruan Tinggi hendaknya dapat mengkomunikasikan pesan-pesan pemasaran Perguruan Tinggi yang diharapkan pasar. Sekolah sebagai lembaga ilmiah akan lebih elegan apabila bentuk-bentuk komunikasi disajikan dalam bentuk/format ilmiah, seperti menyelenggarakan kompetensi bidang studi, forum ilmiah/seminar dan yang paling efektif adalah publikasi prestasi oleh media independen seperti berita dalam media massa, komunikasi yang sengaja dilakukan sekolah dalam bentuk promosi atau bahkan iklan sekalipun perlu menjadi pertimbangan. Bentuk dan materi pesan agar dapat dikemas secara elegan namun menarik perhatian agar sekolah tinggi tetap dalam image sekolah Tinggi sebagai pembentuk karakter dan nilai yang baik. Publikasi yang sering dilupakan namun memiliki pengaruh yang kuat adalah promosi "mouth to mouth" (mulut ke mulut). Alumni yang sukses membagi pengalaman (testimony) atau bukti keberhasilan sekolah Tinggi. Komunikasi pemasaran pendidikan dapat mengunakan strategi komunikasi pro-aktif (proactive strategies).

b. Differensiasi.

Differensiasi; adalah strategi yang memberikan penawaran yang berbeda dibanding penawaran yang diberikan kompetitor, strategi differensiasi mengisyaratkan perusahaan mempunyai jasa atau produk yang mempunyai kualitas ataupun fungsi yang bisa membedakan dirinya dengan pesaing. Strategi differensiasi dilakukan dengan menciptakan persepsi terhadap nilai tertentu pada konsumen. Misalnya: persepsi mengenai inovasi produk, brand image yang lebih unggul, dan lain-lain.

c. Bauran pemasaran (marketing mix)

Bauran pemasaran adalah terkait dengan kegiatan mengenai produk, harga, promosi, dan tempat atau yang lebih dikenal dengan sebutan 4P, yaitu product, price, promotion, dan place dan 7 p yaitu product (produk jasa), price (harga jasa), promotion (promosi), person (sumber daya jasa), physical evidence (bukti fisik/sarana prasarana), dan process (manajemen layanan jasa) untuk pemasaran jasa.

Unsur nilai pemasaran (heart share) meliputi brand, service, dan process;

a. Brand Image; Konsumen dalam membeli sesuatu sebenarnya bukan hanya sekedar membutuhkan barang tersebut, tetapi ada hal lain yang diharapkan dibalik barang tersebut. Citra (image) adalah impresi perasaan atau konsepsi yang ada pada public 
mengenai perusahaan, mengenai suatu obyek, orang atau mengenai lembaga. Citra terbentuk dari bagaimana lembaga melaksanakan kegiatan operasionalnya yang mempunyai landasan utama pada segi layanan. Banyak cara dapat dilakukan untuk menarik perhatian publik dalam rangka pembentukan image terhadap lembaga pendidikan baik melalui daya tarik fisik bangunan maupun daya tarik yang bersifat akademik.

b. Service dan process; pelayanan Perguruan Tinggi terlihat sebagai apa yang diharapkan konsumen. Kesenjangan yang sering terjadi adalah adanya perbedaan persepsi kualitas maupun atribut jasa pendidikan.

\section{Simpulan}

Hasil penelitian ini dapat disimpulkan bahwa konsep pemasaran STIT Madani Yogyakarta meliputi; (1) membentuk team marketing, yang khusus menangani pemasaran STIT Madani Yogyakarta. (2) setiap kegiatan manajemen pemasaran berlandasan dengan etika dan norma nilai-nilai Islam yang bersumber dari Al-Quran dan As-sunnah (3) dalam setiap kegiatan pemasaran berpedoman dengan moment time yang ada agar promosi yang dilakukan lebih menggena dan tepat sasaran. (4) menciptakan dan memupuk brand dengan mendekatkan diri dan mengenalkan STIT Madani Yogyakarta ke area terdekat STIT Madani Yogyakarta.

Faktor Pendukung dan penghambat Manajemen Pemasaran Perguruan Tinggi Di STIT Madani Yogyakarta. Faktor Pendukung yaitu; (1) Mempuyai link perwakilan di seluruh Indonesia dan beberapa negara tetangga. (2) Produk yang ditawarkan terdapat diferensiasi dengan STIT yang lain. (3) SDM yang muda sehingga kerjanya masih sangat produktif. Faktor Pengambat yaitu; (1) Masih banyak masyarakat yang belum mengenal STIT Madani Yogyakarta (2) Sistem manajemen yang masih berubah-ubah. (3) Cuaca dan kesiapan kesehatan bagian marketing .

Implementasi pemasaran STIT Madani Yogyakarta sebagai berikut; (1) Strategi pemasaran; dalam mengidentifikasi pasar STIT Madani Yogyakarta membagi beberapa tingkatan pangsa pasar yaitu perwakilan, pondok pesantren, MAN, SMA/SMK/MA Muhammadiyah, SMA/SMK negeri. Target pemasaran STIT

Madani Yogyakarta lebih di perioritaskan ke luar jawa tetapi tidak tidak menutup kemungkinan pangsa pasar di jawa juga. Dalam menciptakan postioning di masyarakat STIT Madani telah menfokuskan bahwa STIT Madani Yogyakarta sebagai kampus Islam, berasrama serta bermanhaj/ideology salafy/salafus-sholeh. (2) Taktik pemasaran; dalam selling diperlukan adanya bauran pemasaran yang didalamnya harus terdapat diferensiasi sehingga dapat membedakan dan memudahkan dalam memasarkan produk kepada konsumen. Untuk menghindari penipuan dan pembohongan maka dilakukan bauran pemasaran yang berbedabeda pada setiap tingkatan; yaitu gradasinya, pembeda pada setiap tingkatan, penyampaianya, persentasi yang dimunculkan. Karena setiap tingkatan dibutuhkan bauran pemasaran berbeda-beda. (3) Unsur nilai masuk pada setiap kegiatan pemasaran 


\section{Daftar Pustaka}

Ara Hidayat \& Imam Machali, (2012) Pengelolaan Pendidikan Konsep, Prinsip, Dan Aplikasi Dalam Mengelola Sekolah Dan Madrasah, Yogyakarta: Kaukaba.

Buchari Alma. (2007). Manajemen Pemasaran Dan Pemasaran Jasa, Bandung: Alfabeta

Buchori Alma \& Ratih Hurriyati. (2009) Manajeman Corporate \& Strategi Pemasaran Jasa Pendidikan Focus Pada Mutu Dan Layanan Prima, Bandung: Alfabeta.

Dudung Abdurrahman. (2003). Pengantar Metodologi Penelitian, Yogyakarta:Kurnia Kalam Semesta.

Tim Dosen Administrasi Pendidikan Universitas Pendidikan Indonesia. (2011). Manajemen Pendidikan, Bandung: Alfabeta. 